\title{
Manifestation of Translation Strategies via Think-aloud Protocol
}

La manifestación de las estrategias de traducción del protocolo Think-aloud

Samaneh Rahnama*

Islamic Azad University - Iran

samaneh.rahnama1@yahoo.com

\begin{abstract}
This study was concerned with the effect of think-aloud method on the translation process. The aim of this study was to examine differences between translators in the implementation of Newmark's strategies in translating general texts from English into Persian. Four students (three females and one male) majoring in Translation Studies participated in this study. The researcher used a mixed-method design. In the qualitative phase of the study, the data were collected through the think-aloud protocol, translation task, and cassette recorders. The results suggested that there was no significant difference between translators in the implementation of Newmark strategies with regard to translation tasks. During the quantitative phase of the study, the researcher examined the difference between the translators in implementing translation strategies while translating general texts from English into Persian. In this phase of the study, the data were analyzed using SPSS 19 performing Chi-square. The results of this phase proposed that there was statistically no significant difference between the four translators with regard to most of the translation strategies.
\end{abstract}

Keywords: Think Aloud Method, Translation Process, Translator Mind, Mixed Method Design

\section{RESUMEN}

Este estudio tuvo que ver con el efecto del método de pensar en voz alta en el proceso de traducción. El objetivo de este estudio fue examinar las diferencias entre los traductores en la implementación de las estrategias de Newmark en la traducción de textos generales del inglés al persa. Cuatro estudiantes (tres mujeres y un hombre) que se especializan en Estudios de Traducción participaron en este estudio. El investigador utilizó un diseño de método mixto. En la fase cualitativa del estudio, los datos fueron recolectados a través del protocolo de pensar en voz alta, tarea de traducción y grabadoras de cassette. Los resultados sugieren que no hubo diferencias significativas entre los traductores en la implementación de las estrategias de Newmark con respecto a las tareas de traducción. Durante la fase cuantitativa del estudio, el investigador examinó la diferencia entre los traductores en la implementación de estrategias de traducción al traducir textos generales del inglés al persa. En esta fase del estudio, los datos se analizaron utilizando SPSS 19 realizando Chi-cuadrado. Los resultados de esta fase propusieron que estadísticamente no hubiera una diferencia significativa entre los cuatro traductores con respecto a la mayoría de las estrategias de traducción.

Palabras clave: método Think-Aloud, proceso de traducción, mente del traductor, diseño de métodos mixtos

* Islamic Azad University, Quchan Branch, Quchan, Iran. Master's Degree in English Translation, Islamic Azad University, Quchan Branch

Recibido: 17/05/2019 Aceptado: 19/08/2019 


\section{Introduction}

Research into Translation Studies, as a distinct discipline, has recently focused on process-oriented research through which the researchers can explore the mental processes of the translators (Laviosa, 2008). Translation research has undergone major changes during the last two decades, addressing psychological and cultural issues in translation (Mason, 2008), and the academic discipline of translation aims at investigating individual differences in translation (Miyake \& Friedman, 1998). However, little attention has been given to the psychological traits of the learners majoring in translation. Since processes take place in the mind of translators can't be observed directly; researchers employ different methods to reveal nature of these processes.

The process-oriented analysis is a naturalistic study to investigate the translator's internal decision-making process. It is supported by instruments for data collection as consecutives or retrospective think aloud protocols (Ericsson \& Simon, 1993). One of the instruments applied for achieving this goal is think aloud protocol. As explained by Jääskeläinen (2002), in think aloud technique, learners are requested to "verbalize what they are thinking while they carry out a translation task" (p. 108). The aim of think aloud protocol is to obtain a better understanding of psychological and linguistic activities involved in act of translation (Lorscher, 1991). Internal translation process concerns mental activities, which can't be studied directly, therefore tends to be studied by method that is borrowed from cognitive psychology especially verbalizing methods (Bernadette \& Carl \& Zock \& Jacobson, 2011). Ericsson and Simon (1993) believe that verbalization take place on three levels of thought processing, level of articulation, level of description of the content and level of interpretation of thoughts.

The purpose of this study was to ask translators to produce their translations at the same time verbalizing whatever happens in their minds. Audio recordings were analyzed in order to investigate strategies applied by the translators during translation task by the use of Newmark's strategies. This study aimed at exploring the extent to which translators use Newmark (1988) translation strategies in their translations using think aloud protocols and examining the significant difference between the translators in implementing translation strategies while translating general texts from English into Persian. The present study describes translation process by observing translators' behaviors and performance. This study seeks to find answers for the following questions:

1. To what degree do translators use Newmark (1988) translation strategies in their translations?

2. Is there any significant difference between the translators in implementing translation strategies while translating general texts from English into Persian?

\section{Literature Review}

\section{Definition of Translation and Its Nature}

Hatim and Munday (2004) defined translation as "the process of transferring a written text from source language to target language" (p.6). In a developmental study by Krings (1987), translation was seen as a mediation which undergoes two main overlapping phases, namely analysis and synthesis. These phases can be investigated through a retrospective reconstruction of the process on the basis of the relationship between SLT (input) and TLT (output).

The translation model that has been proposed by Newmark (1988) and used in this study is comprehensive and has 18 categories. The followings are the procedures presented by him (p. 81-93):

Literal translation: it ranges from one word to one word, through group to group, collocation to collocation, clause to clause, and sentence to sentence.

Through-translation (claque): the literal translation of common collocations, names of organizations, the components of compounds, and perhaps phrases. To transfer a SL word or expression into the Target Text using a literal translation of its components.

Transference, (borrowing): transferring a SL word to a TL text as a translation procedure.

Naturalization: adapting a SL word first to the normal pronunciation, then to the normal morphology of the TL

Synonym: to use a near TL equivalent to an SL word in a context, where a precise equivalent may or may not exist.

Transposition/ shift: a change in the grammar from SL to TL. singular to plural; position of the adjective, and changing the word class or part of speech.

Recognized translation: use of the official or generally accepted translation of any institutional term.

Functional equivalent: to neutralize or generalize a SL cultural word by using a culture-free word.

Descriptive equivalent, (expansion): to neutralize or generalize a SL cultural word by using a description: the meaning of the word is explained in several words.

Componential analysis: to split up a lexical unit into its sense components.

Compensation: when loss of meaning, sound-effect, metaphor or pragmatic effect in one part of a sentence is compensated in another part, or in a contiguous sentence.

Paraphrase: amplification or explanation of the meaning of a segment of the text.

Note, additions, glosses: When the translator supplies additional information in the form of footnotes, endnote, and glossaries at the end of the text, or within the text.

Modulation: when the translator reproduces the message of the original text in the TL text in conformity with the current norms of the TL. the SL and TL may be different in terms of perspective. 
Deletion: SL word is omitted in the TL.

Couplet: when the translator combines two different procedures.

Cultural equivalent: it is considered as an approximate translation where an SL cultural word is translated by a TL cultural word.

Translation label: an approximate equivalent or a new term that is usually a collocation.

\section{Descriptive Translation Studies}

Descriptive translation studies try to recognize the laws of translation (Toury 1980). According to Bell (1991) "the aim of translation is to produce as accurately as possible all grammatical and lexical features of the SL original by finding equivalents in the TL" (p.13). DTS was developed by Toury in his seminal descriptive translation studies and beyond (Munday, 2001). Brownlie believed that "DTS aims to describe rather than prescribe how translations should be done. The descriptive approach to translation studies laid the foundations for further developments, notably approaches using corpora and tools from corpus linguistics, as well as approaches that are sometimes referred to as the cultural turn in translation studies and which foreground the role of translation as cultural vector" (p.3). In DTS, it is necessary to analyze three aspects: the product, the process that originated the product and the function of the translated text within the textual system of the target culture (Giraldo, 2005).

\section{The Origin of Think Aloud Method}

The theory that verbal protocols can be used to elicit data on cognitive process was proposed by Ericsson and Simon (1984) and they have perceived empirical support for it. They believed that subjects can generate verbalizations subordinate to task driven cognitive processes without changing the sequence of their thoughts and slowing down. The other name of think aloud protocol is verbal protocol analysis. This technique has rooted in psychology. Psychologists use think aloud method to study processes of individuals while they are completing a task. Ericsson and Simon (1984) argued that "think aloud method traces back to the works of experimental psychology and first was described by Karl Duncker while he studied productive thinking" (p.10). According to Newell and Simon (1972), "the first think aloud tapes were transcribed in 1957 and the tradition in the use of verbal protocols was started as a technique to check computer models of information processing" (cited in Ghonsooly, 1997, p.76).

The theoretical method of TPA comes from cognitive psychology, accordingly information stored in different places, some of them in short memory characterized as easy access and limited storage capacity and some of them in long term memory which is more difficult to access and larger storage capacity (Ericsson \& Simon, 1993). "Since 1980, think aloud protocol have mainly been used to ask questions about the temporal dynamics of cognitive processing. They involve asking writers to express their thoughts during a writing task without making any judgment" (p.29). The central assumption of protocol analysis is that "it is possible to instruct subjects to verbalize their thoughts in a manner that doesn't alter the sequence of thoughts mediating the completion of a task. The data collected in this way can serve as valid data on thinking." (Ericsson \& Simon, 1993). Ericsson explained that the closet connection between thinking processes and verbal reports are found when participants are instructed to verbalize their thoughts while focusing on a task. This technique has come to be known as think aloud and it involves the concurrent vocalization of one's inner speech without offering any analysis or explanation (Dornyei, 2007).

According to Krings (1986), "the think aloud technique provides direct means of access to the translation process." (p.266). We can perform a think aloud interview in two way: ether the participants were asked to verbalize their thoughts as they are doing tasks (concurrent think aloud) or the participants describe their experiences after the task are completed (retrospective think aloud). Both are simple method for gaining insight into the participants' thought processes. (Tobii Technology, 2009).

\section{Think Aloud Protocols in L2 Learning}

In second language learning, think aloud protocol has been used to investigate reading and writing strategies of non- native speakers. "Leow and Morgan- Short (2004) first empirically addressed the issue on reactivity on L2 acquisition. The act of thinking aloud potentially triggering changes in learners' cognitive processes while performing a task" (As mentioned by Yoshida, 2008a, p.131). Think aloud protocol has been used to investigate the behaviors of readers and cognitive processes take place during reading (Afflerbach \& Johnston, 1984). Bereiter and Bird (1985) analyzed students think aloud protocols in order to see if a particular strategy were correlated to improved student performance on the comprehension test. No correlation was found. Li and Munby (1996) examined reading strategies of second language learners. They used to think aloud protocol to investigate reading processes of these students. Their result showed that readers frequently used strategies such as translation, background knowledge, self-questioning, and finding topic sentences. Investigators have been applied think aloud method in writing processes of second language learners in order to explore writing strategies and skills of these learners (cited in Hijikata, Nakatani, \& Shimizu, 2012)

Alhaisoni (2012) investigated the writing strategies used by 16 Saudi EFL. He employed think aloud method to gain insight into thought processes utilized by the Saudi learners. Also, semi structured interview was performed. 
Students wrote compositions in L1 Arabic and L2 English. Analysis of the data revealed that strategies were used more frequently when students wrote in English rather than they wrote in Arabic. In addition, specific strategies used when writing in Arabic.

\section{Think Aloud Protocol in Translation Studies}

The use of thinking aloud protocol in studying the translation process provides a valuable source of data about the sequence of events that occur while translators are performing their cognitive task (Chan \& Pollard, 1994). The methodology of think-aloud protocol was first validated by Ericsson and Simon in the 1980. Think aloud method originates from psychology, where it has been used to study how subjects solve mathematical or puzzles (Ericsson $\&$ Simon, 1984). Kring compared a think aloud group with a non-think aloud group and noted that thinking aloud led to more target text revisions (1986).

Jakobsen (2003) observed that thinking aloud reduces translation speed and forces translators to process text in smaller segments. Kunzli (2007) conducted an analysis of the think aloud protocols from professional translators who were asked to revise three draft translations. The analysis revealed a number of ethical problems and loyalty conflicts between different parties involved in revisions.

There are two kinds of think aloud: retrospective or concurrent think aloud. In retrospective think aloud participants should verbalize what they are thinking after completing the task while in concurrent think aloud participants are requested to recall what they are thinking during the process of performing the task (Yoshida, 2008). Eftekhari and Aiminzadeh (2012) examined the strategies 12 senior translation students of Islamic Azad University Bandar Abbas Branch apply while translating literary texts using think aloud protocols. Based on the findings, fourteen strategies were detected. Look-up was the most frequent strategy used by the participants.

Moghadas and Sharififar (2014) asked five professional translators to verbalize their mental processes while translating the text. There was a neologism in the source text. The main focus of the research was on the cognitive processes of this neologism translation. The result indicated that professional translators did not use one single way of performing a translation task and the complexity of the process of problem solving depend on the translation competence of translators.

\section{Method}

\section{Participants}

Four students (three females and one male) majoring in Translation Studies participated in this study from Islamic Azad University of Quchan. Participants have had six years of academic education in the field of translation studies. Their background knowledge of translation theories and practice would guide them in verbalizing their thoughts. Subjects were asked to verbalize whatever comes to their minds during translating text in five sessions. All of them were selected based on convenient sampling and their age was between 24 and 34 . Participants allowed the researcher to record their voices. Participants were permitted to use bilingual or monolingual dictionaries in order to check the meaning of the words. Subjects delivered drafts and written translations to the researcher for further analysis.

\section{Instrumentations}

Sources of data collection in this study were think aloud protocol, translation task, and cassette recorders.

\section{Think-aloud protocol}

Think-aloud protocol is a technique in which students verbalize their thoughts as they bring into the open the strategies they are using to understand a text or to translate a text. It can be used as both an instructional tool and as an assessment of students at almost any grade level. (Coiro, 2001, p.4). The written transcripts of recordings are called think aloud protocol. Think aloud as a data collection method provides access to conscious processing and emotional responses. This method is arduous and time consuming, the resulting data usually rich. (Baker \&Saldanha, 2009).

\section{Translation tasks}

It contained two short passages which were taken from select reading book intermediate level. This book was written by Lee and Gundersen in 2006. The passages of this book contained a wide range of genres collected from sources such as The Wall Street Journal, The Utune Reader and National Public Radio. The participants translated one text per session. Texts were selected through purposive sampling; it means that the chosen texts encompassed Newmark's translation strategies mostly. The field of texts was general because students need no technical skill during translation. The first task used in this study was a text of 210 words on computers. The second task was a text about culture about 240 words. The third task was the text of the first session. It was given to students in order to check that the same result were obtained.

\section{Cassette recorder}

Cassette recorder was used as a tool for recording translators verbalized thoughts and utterances. "Audio recording 
of think aloud give the opportunity to capture spoken interaction of students when developing the think aloud." (Cardenas \& Montes, 2008, p.208).

\section{Procedures}

The data collection for each participant was performed in the following way. The two beginning sessions were devoted to training think aloud technique to students. In these two sessions, the researcher practiced thinking aloud technique with students on 2 texts. Meetings were held in a quiet room in Quchan University. Students had 40 minutes to translate the text and answer the observer questions. First, the researcher visited each student individually. Second, the researcher sat in front of participants and observed their behaviors and performance.

Third, the researcher asked the subjects to translate English texts into Persian. Participants translated texts based on Newmark's translation model. Participants verbalized their thoughts into their mother's tongue. In the last session, students were given the text of first session. Translation tasks were the same for all participants during three sessions. Fourth, the interviewer recorded translators' verbalizations as working on the task. Later, audio recordings transcribed by the researcher. Then, the frequency and percentage of applied strategies had been identified.

\section{Design}

The present study had a mixed method design using both qualitative and quantitative research because mixed method research yields a much more comprehensive result. During the qualitative phase of the study, the researcher attempted to find out the extent to which translators use Newmark (1988) translation strategies in their translation. Also, during the quantitative phase of the study, the researcher aimed at examining the difference between the translators in implementing translation strategies while translating general texts from English into Persian.

\section{Data Analysis}

The first step in data analysis is to transform recordings into a textual form (Dornyei, 2007). Transcriptions have been analyzed in order to understand cognitive process that occurs in the black box of translator. Newmark's translation model has been consider as a criteria for evaluating students, translations. The researcher of this study used statistical software to verify the hypothesis. Data were analyzed by the use of SPSS software 19. Chi square was used to show significant difference in implementing translation strategies by students.

\section{Results and Discussion}

To testify the truth or falsity of the research hypothesis and to explore the research questions, the researcher analyzed the relevant data. In the first step of the study, to find out the degree to which translators used Newmark's translation strategies in their translations, think aloud protocol was used. In the next step, chi-square was used in order to show the significant difference between the translators in implementing translation strategies while translating general texts from English into Persian. All of the participants used bilingual dictionary except participant $\mathrm{C}$ who used monolingual dictionary. Participants read the text one time before beginning the act of translation. When the participants didn't know the meanings of the words they checked them in the dictionary. Sometimes, they guessed the meaning of the words. They always translate titles at the final stage. Students tried to put their translations in their mother language.

\section{Results of Qualitative Phase (Think aloud protocl)}

\section{Result from Task One}

\section{Transcription and Analysis}

Student A: [I usually read the text completely. I decide about the title at the last step... The name of author and proper nouns must be transferred into target language. I'm going to add some words to my translation version...I always circle the unknown words during first reading process of the text...I think it isn't necessary to translate the word in the parenthesis. For the word technician, I don't write an equivalent. I prefer to translate it directly...I know the meaning of the word heart but I prefer to search it in bilingual dictionary to make sure about its meaning].

Analysis of the Student A's Transcription: Translator compared English and Persian structures with each other then write best translation. During the translation process, she always concerns about Persian readers.

Student B: [First, I read the whole text. I'll translate the text paragraph by paragraph. I underline difficult words in the first paragraph then translate it completely and go to the next paragraph. I don't find the meanings of all words one at the time...I don't know the meaning of the word merger. I check it in the bilingual dictionary...I should translate see into the heart of computer connotatively because it is an expression. I think this sentence tries to tell us Suleyman is good at using computer. Now, I translate title at the bottom of paper].

Analysis of the Student B's Transcription: It is obvious that the translator prefers to check the meaning of unknown words in the bilingual dictionary in order to find a Persian equivalent. Student tried to focus on English structures 
and close her translation into Persian.

Student C: [First, I read the text completely. I usually translate the title at the final stage. I read the text one time in order to underline difficult words. I will find the meaning of the underlined words in monolingual dictionary and then begin the act of translation...I think see into the heart of sth is an expression. Translator says I prefer to translate it connotatively... Now, I translate the title. I write its translation at the bottom of paper. It is a free translation because I add some words into the original text].

Analysis of the Student C's Transcription: She didn't know the meaning of many words. If she had some background knowledge about this text, she will translate the text faster. Student $\mathrm{C}$ utters the translation in informal manner but write it formally. This is due to the interference from L1She adds some words to the text and manipulates some parts of it. She utilized strategies inadvertently during the act of translating.

Student D: [I usually translate the text as I read it. I translate the text from A to Z and mark unknown words. I don't know the meaning of the word whiz I think it refer to the sound of bee. I check it in the dictionary. I didn't find it in the bilingual dictionary so I search it in the monolingual dictionary... I guess the word merger is related to the word disparate... I write connotative meaning of the expression can see into the heart of computer].

Analysis of the Student D's Transcription: this student manipulated the source text because he tried to convey the main idea. His translation technique is free. He wasn't too panic to be closed to English language. He attempted to translate unknown words by referencing them to other words. He guessed the meanings of unknown words then check them in the dictionary.

\section{The Frequency of Strategies Employed by Students with Respect to Task One}

The result of this section is summarized in Table 1.

Table 1.

Translation Task One with Regard to Newmark Strategies

Strategy Student A Student B

Valid Transposition

Transference Frequency

Through translation

Literal translation

Addition

Descriptive Equivalent

Functional equivalent

Cultural equivalent

Deletion

Synonymy

Paraphrase

Modulation

Total

13

7

10

2

1

2

1

2

2

1

30

28

$\begin{array}{cc}\text { Student C } & \text { Student D } \\ 8 & 7 \\ 11 & 14 \\ 2 & 3 \\ 1 & \\ & 3 \\ 1 & 1 \\ 1 & 1 \\ 2 & 3 \\ 2 & 1 \\ 1 & 2 \\ 29 & 35\end{array}$

\section{Result from Task Two}

\section{Transcription and Analysis}

Student A: [I always use a fixed technique during the translation process. I read the text completely and underline unknown words and difficult words at the same time in order to check them later in the dictionary. I may use both bilingual and monolingual dictionaries... Driving us crazy is an expression; I try to translate it in a way to convey its meaning. We don't have any Persian equivalent for the word traffic. I shall transfer it. The legal drinking age is a phrase that represents European's culture about drinking. We don't have an exact equivalent for this phrase so I translate it word by word...As the last step, I translate the title. I add the word journal to the title].

Analysis of the Student A's Transcription: She followed certain procedures during the translation process. After translating each paragraph, she reads the text in order to edit it. The translator paid attention to the grammatical structures during the translation process. She compared the cultural words with words in her culture.

Student B: [First, I read the whole text and underline unknown words such as hectic and warp and check them in bilingual dictionary. Since these words have several meanings, I should convey their contextual meaning. I don't translate the phrase in the air because I believe that we don't feel anything in the air. I translate next sentence at the final step because it's challenging for me. I don't know how to translate warp speed. I read the sentence again. I translate the title before editing my translation]. 
Analysis of the Student B's Transcription: She translated the text as usual. Some parts of texts were challenging for her. She checked the meanings of simple words in the dictionary in order to find a better equivalent. She concerned about structures. Fluency and acceptability of translation is important for her. She tried to be close as much as possible to the TL.

Student C: [I read the text completely and at the same time underline unknown words. I translate first sentence literally. I search the words hectic and warp in the monolingual dictionary. Legal drinking age refers to the American culture. This text compares lifestyles of Americans and Australian. As the last step, I translate the title].

Analysis of the Student C's Transcription: For this student, the second task was easier than the first task. The translation technique of this translator was the same as last sessions. Translator used bilingual dictionary two times.

Student D: [First, I read the text one time. Boston Globe is a proper name. I guess it is name of a newspaper so I'd prefer to transferee it. I use metonymy technique to translate steering wheel. I don't know the meaning of the word warp. I don't check it in the dictionary. I can guess its meaning from the context. Drink in this text is a cultural word. It refers to the alcoholic drinks. Not to mention is an expression that doesn't have Persian equivalent].

Analysis of the Student D's Transcription: Translation of this text was easy for the translator. He translated some words by guessing their meanings. He used dictionary two times. Because this text was about culture, translator compared it with Iranian culture. He tried to translate the text freely.

\section{The Frequency of Strategies Employed by Students with Respect to Task Two}

The result of this section is summarized in Table 2 .

Table 2.

Translation Task Two with Regard to Newmark Strategies

$\begin{array}{llllr} & \text { Student A } & \text { Student B } & \text { Student C } & \text { St } \\ \text { Strategy } & \text { Frequency } & & & \\ \text { Valid Transposition } & 1 & 1 & 9 & 3 \\ \text { Transference } & 12 & 9 & 2 & 8 \\ \begin{array}{l}\text { Through translation } \\ \text { Literal translation }\end{array} & 3 & 3 & 1 & 2 \\ \text { Addition } & 1 & 2 & & 2 \\ \text { Deletion } & 4 & & & 24 \\ \text { Paraphrase } & 1 & & 14 & \\ \text { Modulation } & 1 & 15 & \end{array}$

\section{Result from Task Three}

\section{Transcription and Analysis}

Student A: [I read the text completely and underline its unknown words. Although this is second time I reading this text, I'd prefer to translate its title at the end. I break down theses long sentences into short sentences. When I translate this text for the first time, I had problems with long sentences. Again, I don't translate the word in parenthesis. When in English a sentence begin by phrase and comma and subject come at the end. In Persian, we reverse it.

Also, I transfer name of company directly into TL. I don't check the word October to which month refer. Driving somebody crazy is an expression. Although we have a Persian equivalent for the word email, I'd like to transfer it directly. I translate sophomore by describing it].

Analysis of the Student A's Transcription: Student translated text faster than first time. She known meanings of all words. She didn't use dictionary during the translation process. Long sentences weren't trouble making for the translator. Familiarity with the text increased speed of translation and thinking aloud.

Student B: [I always used to read the text completely and then translate it sentence by sentence. As I am reading the text, I underline unknown words. I'll edit the text paragraph by paragraph and I'll translate the title at the end. I think the familiarity with the text will have an effect on my translation. Because I am familiar to many words, I don't need the dictionary.

In the second sentence, I move the subject from end of sentence to the beginning part. I transfer name of company and persons directly into TL. I translate theses long sentences into short sentences. I translate the expression see 
into the heart of something connotatively. This expression tries to show Suleyman's ability and skill in the field of computer. Now, I can decide about title].

Analysis of the Student B's Transcription: As usual, the translator talked about her translation method. She read the text sentence by sentence while uttered her thought. Student translated the text for the second time this familiarity with the text increased her translation speed. Also, she faced no new problem. Last time student had a problem with the translation of proper nouns but now this problem has been removed.

Student C: [I read the text rapidly in order to find unknown and difficult words. I translated this text before so I know most of its words. As usual, I translate title at the end. I translate words such as email, technicians as it is. See into the heart of something is an expression. These long sentences aren't trouble making for the second time. Now, I translate the title. Wall Street is name of a magazine. When you have some information about the text, you can thinking aloud the text better].

Analysis of the Student C's Transcription: Familiarity with the text had an effect on translation process. Student translated this text faster than first time. Since the student translated the text last month, it wasn't trouble making for her. This familiarity had an effect on the process of thinking aloud.

Student D: [I translate the text as I read it sentence by sentence. I translate these proper names directly.I'd prefer to give an equivalent for the word technologies but last time I transfer it directly. I don't translate the word in the parenthesis like first session. I break down long sentences into short sentences or I join sentences with conjunctions. See into heart of something is an expression I translate it sense by sense. Now, I read the translation and edit it at the same time].

Analysis of the Student D's Transcription: the researcher understood for this translator familiarity with the text increased translation speed and thinking aloud .Student didn't use dictionary. The pervious problems had been solved this time.

\section{The Frequency of Strategies Employed by Students with Respect to Task three}

The result of this section is summarized in Table 3.

Table 3.

Translation Task Three with Regard to Newmark Strategies

$\begin{array}{lllll}\text { Strategy } & \begin{array}{l}\text { Student A } \\ \text { Frequency }\end{array} & \text { Student B } & \text { Student C } & \text { Student D } \\ \text { Valid Transposition } & 8 & 5 & 8 & 7 \\ & & & & 14 \\ \text { Transference } & 14 & 15 & 11 & 2 \\ \text { Through translation } & 3 & 2 & 1 & 2 \\ \quad \text { Addition } & 1 & 2 & 1 & 1 \\ \text { Descriptive Equivalent } & 1 & 1 & 1 & 2 \\ \text { Functional equivalent } & 1 & 3 & & 1 \\ \text { Deletion } & 1 & 1 & 23 & 30 \\ \text { Synonymy } & 29 & 30 & \end{array}$

\section{The Quantitative Phase}

To see if the difference between the translations is statistically significant, the researcher performed Chi-square. As displayed by Table 3 there was statistically no significant difference between the four translators with regard to the strategies of transposition, transference, through translation, functional equivalent and descriptive equivalent with respect to task one. Indeed, in these cases, the significant value is more than the alpha value of .05. The hypothesis of this study testified with regard to task one.

Table 4

The Significant Difference between Students with Respect to Task One

$\begin{array}{llll}\text { Strategies } & \text { Value } & \mathrm{df} & \text { Asymp.Sig. (2 sided) } \\ \text { Transposition } & 0.506 \mathrm{a} & 3 & 0.918 \\ \text { Transference } & 1.111 \mathrm{a} & 3 & 0.774 \\ \text { Through translation } & 0.444 \mathrm{a} & 3 & 0.931 \\ \text { Functional equ. } & 0.571 \mathrm{a} & 3 & 0.903 \\ \text { Descriptive equ. } & 0.000 \mathrm{a} & 3 & 1.000\end{array}$

To see if the difference between the translations is statistically significant, the researcher performed Chi-square. As displayed by Table 4, there was statistically significant difference between the four translators with regard to the strategy of addition. Indeed, in this case, the significant value is less than the alpha value of .05 (here, it is 0.017 ). However, 
the researcher found no significant difference between the translators with regard to the strategies of transference and through translation. The hypothesis of study rejected with regard to task 2 because there was significant difference between translators with regard to strategy of translation.

Table 5

$\begin{array}{lccc}\text { Table } 4 \text { the Significant } & \text { Difference between } & \text { Students with Respect to Task Two } \\ \text { Strategies } & \text { Value } & \mathrm{df} & \text { Asymp.Sig. (2 sided) } \\ \text { Transference } & 0.923 \mathrm{a} & 3 & 0.820 \\ \text { Through translation } & 0.364 \mathrm{a} & 3 & 0.948 \\ \text { Addition } & 10.222 \mathrm{a} & 3 & 0.017\end{array}$

\section{Discussion}

In this study, familiarity with the text and think aloud technique had an effect on translation speed and thinking aloud the text. It increased translation speed of translators. Translators translated final text faster than the first task. While in Jackobsen (2003)'s study thinking aloud delayed translation speed at about $\% 25$ and no significant effects on revision were found. Furthermore, the result of this study is in consistent with the result of Jackobsen's study. Thinking aloud forced translators to process text in smaller segments. Sometimes, they translate the sentences word by word or divided it into small units. In the study conducted by Lorascher (1991) 48 subjects verbalized their thoughts while performing the task. Reproductions had been transcribed by the researcher.

\section{Conclusion}

The most important conclusion we can draw from the study is that think aloud method has different effects on the translation process of translators. A text which was hard for one translator, was easy for the other translator. Some translators tried to be faithful to ST but others tried to put translation into their mother language. Thinking aloud can't uncover unconscious thought. The difficulty level of the text depends on translator's knowledge and translator's ability. The null hypothesis of the study was testified so we can conclude that there is no significant difference between translators regard to translation of general texts. In sum, the study concludes that attention to the black box of translator could yield useful data.

\section{BIBLIOGRAPHIC REFERENCES}

Afflerbach, P., \& Johnston, D. (1984). Research methodology on the use of verbal reports in reading research. Journal of Reading Behavior, 6(4), 307-322.

Alhaisoni, E. (2012). A think aloud protocol investigation of Saudi English major students writing revision strategies in L1 and L2.English Language Teaching Journal,5 (9), 144-154.

Baker, M., \& Saldanha, G. (2009). Routledge encyclopedia of translation studies. London and New York: Routledge.

Bell, R.T. (1991). Translation and translating: Theory and practice. London and New York: Longman

Bereiter, C., \& Bird, M. (1985). Use of thinking aloud in identification and teaching of reading comprehension strategies. Cognition and Instruction, 2,131-156.

Brownlie, S. (2009). Descriptive vs. committed approaches. Retrieved May 2015 from: www.researchschool.org

Cardenas, A., \& Montes, L. (2009). The impact of think aloud strategy in the English reading comprehension of EFL 10th graders. Retrieved April 2015 from: www.worldwidescience.org

Coiro, J. (2001). Using the think aloud in reading instruction. Retrieved April 2015 from:

Dornyei, Z. (2007). Research method in applied linguistics. Oxford University press.

Easwaramoorthy, M., \& Zarinpoush, F. (2006). Interviewing for research. Retrieved March 2015 from: www. imaginecanada.ca

Eftekhari, A., \& Aiminzadeh, Sh. (2012). Investigating the use of thinking aloud protocols in translation of literary texts. Journal of Theory and Practice in Language Studies, 2(5), 1039-1047.

Ericsson, K.A., \& Simon, H.A. (1984). Protocol analysis: Verbal reports as data. MA: MTT Press.

Ericsson, K.A., \& Simon, H.A. (1993). Protocol analysis: Verbal reports as data. MA: MTT Press.

Ghonsooly, B. (1997). Introspection as a method of identifying and describing competence in reading skills. Iran: Ferdowsi University of Mashhad.

Hatim, B., \& Munday, J. (2004). Translation: An advanced research book. London: Routledge

Hijikata, Y., Nakatani, Y., \& Shimizu, M. (2012). Japanese EFL students reading processes for academic papers in English. Journal of Education and Learning, 2(1), 70-83. Retrieved May 2015 from: www.ccsent.org

Jääskeläinen, R. (2002). Think-aloud protocol studies into translation. An annotated bibliography. Target Journal, $14(1), 17-36$.

Jakobsen, A. (2003). Effects of think aloud on translation speed, revision and segmentation. In 
Krings, H.P. (1986). Translation problems and translation strategies of advanced German learners of French. Tubengen: Narr

Krings, H.P. (1987). The use of introspective data in translation. In Faerch \& Kasper (2eds.), Introspection in second language research. Philadelphia: Multilingual Matters.

Kunzli, A. (2007). The ethical dimension of translation revision: An empirical study. Journal of Specialized Translation, $8(2), 42-56$.

Laviosa, S. (2008). Translation. In R. B. Kaplan, The oxford handbook of applied linguistics. Oxford: Oxford University Press.

Lee, L., \& Gundersen, E. (2006). Select readings. Oxford University Press.

Lorscher, W. (1991).Process oriented research into translation and implication for translation teaching. Traduction, Terminologies, Reduction Journal, 5(1), 145-161.

Miyake, A., \& Friedman, N. (1998). Individual differences in second language proficiency: Working memory as language aptitude. NJ: Erlbaum.

Moghadas, M., Sharififar, M. (2014). A model for cognitive process of neologism translation International Journal of English Language and Translation studies,2(1),1-12.

Munday, J. (2001). Introducing translation studies: Theories and applications London: Routledge.

Newell, A., Simon, H.A. (1972). Human problem solving. NJ: Prentice Hall.

Newmark, P. (1988). A textbook of Translation. NJ: Prentice Hall

Toury, G. (1980). In search of a theory of translation. Telaviv: Porter Institute for poetics and semiotics.

Yoshida, M. (2008a). Think aloud protocols and Type of reading task: The issue of reactivity in L2 reading research. In selected proceedings of the 2007 second language research forum,(ed.) Mellissa Bowles, Rebeca Foote, Silva Perpinan, o Rakesh Bhatt,199-209.

Yoshida, M. (2008b). Are they really thinking aloud? Comparison of thin aloud process between a group administered session in a language laboratory and an individually conducted session. Kyoto: University of foreign studies. 